\title{
Confidence Interventions: Do They Work?
}

\section{Ryan Thomas Williams}

ISSN: 2311-8636 (Print)

ISSN: 2312-2021 (Online)

Licensed:

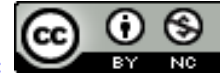

Source of Support: Nil

No Conflict of Interest: Declared

${ }^{*}$ Email for correspondence:

ryan.williams@tees.ac.uk
School of Social Sciences, Humanities and Law, Teesside University, Middlesbrough, Tees Valley, TS1 3BX, United Kingdom

\section{ABSTRACT}

The purpose of the present study was to investigate the effectiveness in different confidence enhancing techniques (Positive Self-Talk, Imagery and Confidence Profiling) in amateur track and field athletes. Fifteen participants volunteered to take part in the study, five in each intervention group. A baseline measure using TSCI and SSCI were administrated prior the intervention. Each athlete then completed a four week intervention, completing the TSCI and SSCI again post intervention. Results from a mixed model ANOVA yielded a significant difference in pre scores to post in each intervention, $p<0.05$. Although no significant difference was found between groups, $p>0.05$, meaning all groups were of equal effect. Despite not being statistically different, imagery improved scores the most. These results provide a protocol structure for psychologists and coaches to follow.

Keywords: Confidence Profiling, Positive Self-Talk, Imagery intervention

\section{INTRODUCTION}

Confidence is defined by Karageoeghis and Terry (2011, pp. 59) as "the certainty that a person is equal to the task at hand as a result of an absolute belief in ability". Confidence within self although can be influenced by a trait (a stable element of personality), is determined by how resilient a person is of that part of personality.

In sporting context, it is widely acclaimed by researchers, theorists and practitioners that confidence is the most critical psychological characteristic influencing performance (see Bandura, 1986; Vealey et al, 1998; Jones and Hanton, 2001). It is suggested the reasoning behind this is fuelled by the influence a dramatic loss of self-confidence has on performance (e.g. choking). Contrastingly it is also thought high levels of self-confidence enhance performance (e.g. clutch performance), however there are inconsistent findings in the literature (see Zinsser, Bunker and Williams, 2006 cited in Hays et al, 2010). Adding to this, too much confidence often called fake confidence can lead to complacency and a decrement of performance.

Given the relationship between self-confidence and successful performance, there is a need for strategies to enable the athlete to perform optimally. Sport practitioners and coaches have made various interventions available, whether through traditional approaches like imagery and positive self-talk or more modern additions to the literature 
such as confidence profiling. Cumming et al (2004) made clear that interventions are seen as an integral part in the process of what makes an athlete successful in elite sport.

This present study will investigate which technique is proven to be most effective when used as an intervention over a four week period, extending the existing literature. The research will also provide a structure for psychologists and coaches to follow by transferring literature into applied settings. By following a psychological skills programme, an approach to different aspects of the interventions will be available for the coach and practitioner. In terms of athlete development, it is hoped that the interventions will promote spiral success rather than temporary improvements.

\section{LITERATURE REVIEW}

\section{Defining Confidence}

Confidence within sport has been described as "the perception of one's own ability affecting athletic performance" (Lirgg, 1991 pp. 294). Confidence throughout research is identified as the psychological characteristic that distinguishes a successful athlete from an unsuccessful athlete. A positive relationship between high levels of self-confidence and successful performance has been well documented (see Feltz and Lirgg, 2001).

Vealey (1986, pp. 223) defines self confidence in sport as "the belief or degree of certainty individuals possess about their ability to be successful in sport". Vealey (1986) continues by separating sport confidence into two categories: 1) State confidence, which is defined as the belief or degree of certainty individuals possess at one particular moment about their ability to be successful in sport; 2) Trait self-confidence which can be defined as the belief or degree of certainty individuals usually possess about their ability to be successful in sport. When understanding confidence, both trait and state need to be considered, as this will enable sport practitioners, coaches and athletes to gain an interactional approach to the issue.

There are different resilient pathways in which confidence can be built for performance success. Vealey and Vernau (2010) identified four stages of building self-confidence 1) Perspiration, 2) Regulation 3) Inspiration and 4) Validation. Interestingly, the last stage is validation, which is achievement of the athlete. This has promoted an interesting debate among researchers as ego orientated athletes define success differently to task orientated athletes.

Vealey (2001) constructed a model combining the different aspects of sport confidence; this was named The Model of Sport Confidence. The model includes four main components: 1) Constructs of sport confidence, describing sport confidence as multidimensional, including the athlete's confidence in regards to development, decision making, psychological skills and physical attributes; 2) Sources of sport confidence, consisting of a number of sub categories which include achievement, social climate and self-regulation (see Vealey et al, 1998); 3) Consequences of sport confidence, made up from behaviours and emotions; 4) Factors affecting sport confidence, including personality characteristics including motivation as well as coaching philosophy. The general consensus among sport psychologists, researchers and theorists is that this model is useful for explaining the relationship between self-confidence in sport and situation specific sport confidence (see Vealey, 2001; Feltz and Lirgg, 2001; Weinberg and Gould, 2011). Model is shown below in figure 1 . 


\section{Factors influencing sport confidence}

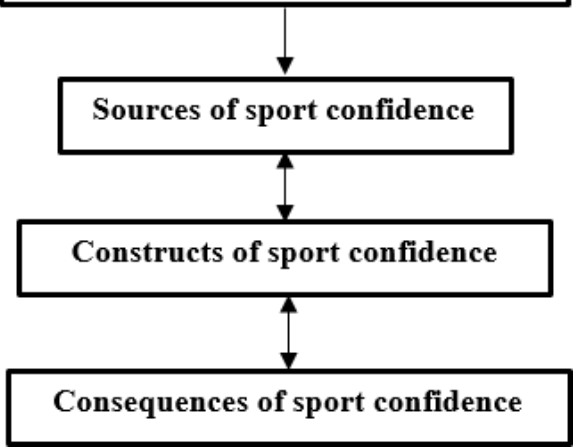

Figure 1. Vealey's (2001) Model of Sport Confidence

\section{Sport Confidence Measures}

Vealey (1986) stated that in every sport self-confidence model there are two main components which make up its structure: sport confidence (SC-state) and trait sport confidence (SC-trait). Before Vealey (1986), there was a need for a measure of both SC-state (State Sport Confidence Inventory) and SC-trait (Trait Sport Confidence Inventory). Horn (2008) supports Vealey's (1986) Trait Sport Confidence Inventory and State Sport Confidence Inventory and advises them to be used together. Both inventories consist of 13 items with scales ranging from 1-9 ( $1=$ low confidence, $9=$ high confidence). The highest score which can be achieved is 117, with the lowest score being 13 .

Vealey (1986) described both inventories as sport specific, considering the distinction between personality traits and states which relate to self-confidence. This is shown as a valid way for testing self-confidence as well as showing consistency in athletes who vary in level, age and ability (see Fung and Chueng, 2001). Beattie et al (2011) also supports the TSCI and SSCI as being the most valid tools available to measure state and trait confidence, thus supporting construct validity of the inventories. More recently Hays et al (2007) developed confidence profiling. Confidence profiling is similar to performance profiling in the sense that they both provide assessment of the athlete with the additional benefit of using it as an enhancement technique. Confidence profiling measures sources and types of confidence, considering a durable and multidimensional belief. Weinberg and Gould (2011) support the idea of using confidence profiling as an assessment tool, describing it as an expansion of Bandura's (1984) Sources of Self-Efficacy.

Vealey (1998) also created the Sources of Sport Confidence Questionnaire (SSCQ). This inventory consists of 42 items with a 7-point likert scale (1- not important, 7- high importance) measuring sources of confidence specific to sport. The SSCQ was established on the basis that a) there is minimal response bias; b) the open ended responses identify additional sources; and c) unambiguous administrating procedures for the athlete. Despite this, Wilson et al (2004) claim that the SSCQ influences SC-trait more than SC-state. This is because sources of confidence appear more internally controllable such as physical/mental preparation and mastery. This is also mentioned as a limitation by Vealey (1998). The SSCQ was first developed using high school athletes, hosting another problem as the factorial structure provided must examine master athletes to determine validity before identifying their most salient sources (see Wilson et al, 2004). 


\section{Confidence, Anxiety and Performance}

A number of studies have indicated that high levels of self-confidence are associated with superior performance (see Weinberg and Gould, 2011; Morris and Koehn, 2004). More specifically, one's belief that a task can be performed successfully has a consistent impact on actual performance (see Hays et al, 2007; Hays et al, 2010; Weinberg and Gould, 2011; Weinberg et al, 2012). Martin and Gill (1991) examined various psychological variables in relation to performance. The study's results showed an interesting trend; athletes who scored higher in the TSCI and SSCI performed skills in their sport more successfully than those with lower scores. Prior studies have noted the importance of self-confidence in relation to performance (see Bandura, 1986). More recent studies are also finding a similar relationship (Hays et al, 2007; Hays et al, 2010).

Jones (1996) suggests that through anxiety we can achieve optimal self confidence levels. It is thought that when an athlete is dealt with a stressor which is often interpreted as anxiety (e.g. butterflies in stomach), it is crucial that athletes are taught how to control the stressor and interpret it as a positive element contributing to enhancing performance (e.g. when butterflies in the stomach are present, the athlete knows this is good for their performance and becomes more confident). This supports Lazurus' (2000) theory that athletes get the opportunity to control the stressor before coping strategies arise, as opposed to stressor straight to bad response. These findings have caused a debate among researchers. Burton and Naylor (1997) claim Jones (1996) has mislabelled anxiety and there is no such thing as a positive contribution from anxiety with regards to performance. Hardy (1997) has since supported Jones (1996) by proposing that the way in which performers interpret anxiety is more important than actual intensity. Despite this difference among researchers, it is agreed that anxiety does influence self-confidence.

Strategies to cope with psychological problems in sport have always been available for the athlete. Some of these include self-talk and imagery, with more modern additions now being introduced such as confidence profiling (Hays et al, 2007). Facilitating an athlete through maintenance of sport confidence needs to consider the sources from which confidence is derived combined with the type of confidence. This will enable an ideographic, contemporary approach to dealing with issues (see Vealey, Hayashi, Garner-Holman, and Giacobbi, 1998). It is also interesting to consider that accomplishments are the strongest source of self-confidence therefore enhancing these feelings of accomplishments have positive effects on performance. A successful intervention is often categorized as successful conditional to the outcomes. Benefits of employing interventions include enhancing performance (through improving the proposed characteristic), as well as a benefit from other emotions and behaviours that are thought to improve the performer (i.e., decrease state anxiety, facilitate concentration and regulate arousal). Greenspan (1989) highlights generalization of athletes as being a potential problem for the researcher when carrying out an intervention. It is suggested that many interventions need to consider individual needs.

\section{MetHOdS}

\section{Participants}

All participants were recruited via email contact made with Teesside University Athletics Club. Additionally, face to face contact was made during one of the club's training session. The study was explained to all track and field athletes and informed consent (Teesside University guidelines) obtained. 
A total of 15 participants were recruited (11 male and 4 female), with a mean average $(M)$ age of 20.87 years $(S D=1.24)$. Participant's involvement in track and field ranged from 2-9 years. Disciplines included $100 \mathrm{~m}, 200 \mathrm{~m}, 400 \mathrm{~m}, 800 \mathrm{~m}, 1500 \mathrm{~m}, 110 \mathrm{~m}$ hurdles, shot put, hammer, javelin and long jump.

\section{Design}

A quasi experimental design has been used within the study. Weinberg et al (2012) also used a quasi-experimental design when looking at the effects of different self-talk interventions. The independent variable is the type of intervention which has been used (group). This has three levels 1) Self-talk, 2) Confidence Profiling and 3) Imagery. The dependant variable is the effectiveness of the intervention on confidence levels.

\section{Materials}

The Trait Sport Confidence Inventory (TSCI) (appendix 1a) and State Sport Confidence Inventory (SSCI) (appendix 1b) were administrated pre and post intervention to measure confidence levels. Both TSCI and SSCI consist of 13 items with scales ranging from 1-9 (1=low confidence, 2 =high confidence). Vealey (1986) confirmed the inventories consider distinction between personality traits and states which relate to confidence. Fung and Chueng (2001) also claimed that using the inventories are a valid way for testing selfconfidence in addition to showing consistency in athletes who vary in level, age and ability.

Hays (2007) confidence profiling (appendix 1c) was selected as an intervention technique; the process asks athletes to think about the most confident moment they have had/still have in sport and write down what they were/are confident in. The athlete then rates that moment on a scale 1-10. Finally, athletes are asked to identify sources of this type of confidence.

Roberton's (2013) hot button approach (appendix 1d) was employed as the positive selftalk group; four columns are created on an a 4 piece of paper. In the first column, athletes identify a situation that creates poor confidence levels, in the second column athletes write down the cause of that situation. The final two columns are negative self-talk where the athlete lists as many negative thoughts related to the situation as possible, and positive self-talk replacement where the athlete is realistic but positive about the situation. Holmes and Collins (2001) PETTLEP model (appendix 1e) was executed as the imagery intervention technique, using MS imagery.

\section{Procedure}

Upon receiving ethical approval to begin the study, the chairman of the University Athletics Club granted access to use athletes within the club. Once ethics had been granted by the university committee, emails were sent to each member of the club inviting them to be part of the study. Each email included a participant information sheet (appendix 2a). Once responses had been received, face to face meetings with the athletes were arranged for a training sessions which they would be present. Informed consent (appendix $2 b$ ) and a general participant questionnaire (appendix 2c) were obtained during these sessions. The following week Vealey's (1986) TSCI and SSCI were administrated to give initial confidence scores pre intervention.

Following Bull's (1989) findings that athletes who are given an education phase benefit more from psychological skills training, it was important than the following two weeks be 
made up of educating the athlete about their intervention technique and confidence in sport. A confidence workshop (appendix 3) was provided for the athletes; this was a group session and contained a PowerPoint presentation at Teesside University library with questions and answers at the end. The session was around forty-five minutes long and was very interactive with the athletes. Each athlete was then randomly allocation to an intervention group using simple randomization however not informed until the following meeting which was a one on one session. Each intervention technique consisted of five participants.

The next session delivered each athlete with information about the intervention technique they were to undergo as well as practice of their intervention. The imagery group practiced imagery using the PETTLEP model. The confidence profiling group identified two types of confidence and listed as many sources as possible for each. The positive selftalk group were asked to list two hot button situations. This was then developed during the four week intervention by adding more hot button situations (self-talk) and types and sources of confidence (confidence profiling). The TCSI and SSCI were administrated again after the intervention.

\section{Data Analysis}

A mixed model ANOVA measures variance within subjects and between subjects was used as main analysis. A 2 time by 3 group mixed ANOVA was used to calculated variance between pre-post results (within subject means) and variance within each group (between subject means). This was calculated using IMB SPSS Statistics.

\section{RESULTS}

Descriptive statistics show that mean average of confidence scores $(T S C I+S S C I)$ in each group increased from pre intervention to post intervention (please see table 1). Post-test confidence scores show that imagery increased by 23.8, confidence profiling increase by 11.8 and self-talk increased 17.6. A mixed model ANOVA revealed that there was a significant effect within subject means, $F(1,12)=15.632, p=0.02, \eta 2=0.566$. This confirms total confidence scores significantly improved once the intervention had been completed (please see figure 2). A clear positive trend is shown in each group, once the intervention had been completed by the athletes, confidence scores increased.

Despite the significant effect found within groups there was not a significant difference found between subject means, $F(2,12)=1.528, p=0.256, \eta 2=0.203$, suggesting there was no difference in effectiveness of intervention type. A post hoc Tukey's HSD test showed no significant effect between comparisons of any group, $p>0.05$ (please see table 2).

Eta squared reported large effect sizes for within (0.566) and between (0.203) subjects, supporting $p$ values for significant effect. This large effect size complements initial thoughts from $p$ values that there is a significant difference from pre to post intervention scores in each group however not between each group.

Further independent $t$ test analysis examined the difference between pre and post scores in athletes who participate in sprinting disciplines compared with other events. This analysis was made due to the success of a local sprint athlete at the European indoor championships. Descriptive statistics show larger improvement in confidence scores post in non-sprint athletes compared with sprint athletes (please see table 3). However, no significant difference was found, $p>0.05$ (please see figure 3 ). 
Table 1. Descriptive statistics of each group pre and post intervention. Scores are that of TSCI and SSCI combined. Note: mean (M), standard deviation (SD)

\begin{tabular}{|l|c|c|c|}
\hline Group & & Scores pre- intervention & Scores post-intervention \\
\hline Imagery & $\mathrm{M}$ & 176 & 199.80 \\
& $\mathrm{SD}$ & 23.09 & 6.41 \\
\hline Confidence Profiling & $\mathrm{M}$ & 161.20 & 173 \\
& $\mathrm{SD}$ & 24.98 & 13.65 \\
\hline \multirow{2}{*}{ Self-Talk } & $\mathrm{M}$ & 156 & 174.40 \\
& $\mathrm{SD}$ & 38.09 & 27.26 \\
\hline Total & $\mathrm{M}$ & 164.40 & 182.4 \\
& $\mathrm{SD}$ & 28.67 & 20.97 \\
\hline
\end{tabular}

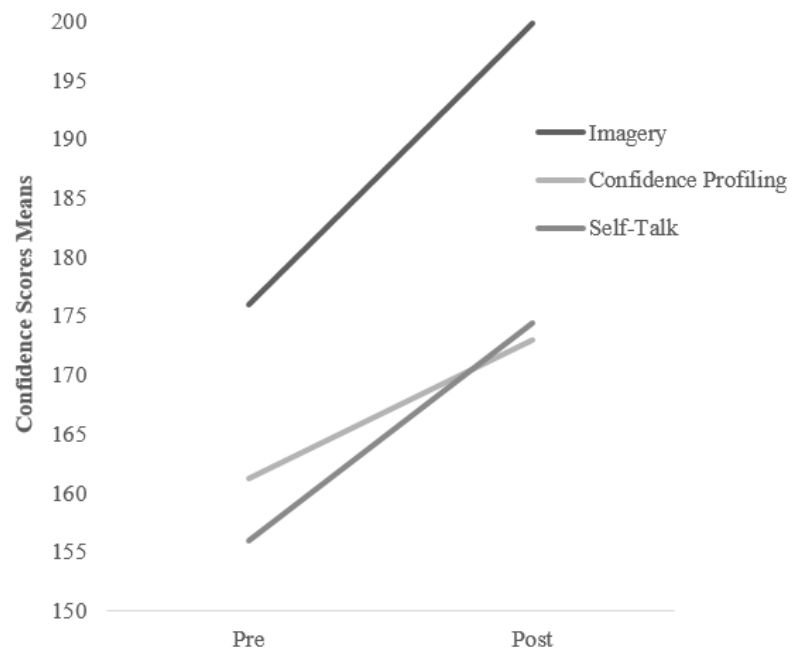

Figure 2. Displaying the significant improvement in confidence scores within each group

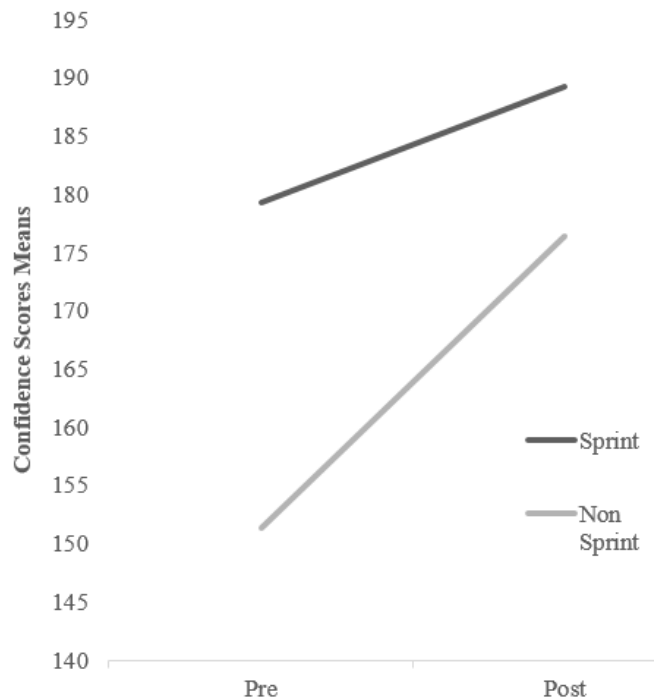

Figure 3. Showing pre-post test scores in sprint vs non sprint athletes 
Table 2. Comparisons for each group. There was no significant difference reported between groups, $\mathrm{p}>0.05$. Note: Imagery (I), Confidence Profiling (CP), Self-Talk (ST)

\begin{tabular}{|c|c|}
\hline Tukey's HSD & \\
\hline Comparison & Sig \\
\hline I - CP & .351 \\
I - ST & .293 \\
\hline CP - I & .351 \\
CP - ST & .990 \\
\hline ST - I & .293 \\
ST - CP & .990 \\
\hline
\end{tabular}

Table 3. Displaying descriptive statistics of athletes in sprint disciplines vs non sprint disciplines, $\mathrm{p}$ values at 0.05 .

\begin{tabular}{|l|c|c|c|c|}
\hline & & $\begin{array}{c}\text { Scores pre } \\
\text { intervention }\end{array}$ & $\begin{array}{c}\text { Scores post } \\
\text { intervention }\end{array}$ & Sig \\
\hline Sprint Disciplines & $\mathrm{M}$ & 179.28 & 189.28 & 0.434 \\
& SD & 24.68 & 21.40 & \\
\hline Non Sprint Disciplines & $\mathrm{M}$ & 151.37 & 176.37 & 0.52 \\
& SD & 26.59 & 19.95 & \\
\hline
\end{tabular}

\section{Discussion}

The purpose of the present study was to investigate which confidence enhancing technique is most effective when improving confidence scores over a four week intervention in track and field athletes. Before discussing the differences in effectiveness, it should be noted that all groups were helpful in improving confidence levels. Results show that the imagery group significantly improved after the intervention (see Jenny et al, 2013). The general consensus is that MS imagery is a valid method to enhance an athlete's confidence (see Evans, Jones and Mullen, 2004; Holmes and Collins, 2001; Martin et al, 1999). The positive self-talk group also improved confidence scores after the intervention. Again, this is well established in previous research (see Hardy, Roberts and Hardy, 2009; Weinberg et al, 2012; Van Raalte et al, 1995). Despite confidence profiling being developed as a measuring tool in addition to a confidence enhancing technique, the present study uses it solely as an enhancing technique. This proved to be successful as an intervention with confidence scores increasing (see Hays et al, 2010).

A mixed model ANOVA showed that total scores had improved significantly after the intervention, $p<0.05$, thus meaning that the intervention process was successful. All three techniques are well documented and well proven to improve an athlete's confidence level (see Weinberg et al, 2012; Hays et al, 2010; Evans, Jones and Mullen, 2004).

Despite this, there was no significant difference found between each group, $p>0.05$, suggesting all groups are of equal effect when improving confidence levels in track and field athletes. No previous research has investigated the differences in types of confidence enhancing techniques, so comparing the present study's findings is difficult. Although some studies such as Weinberg et al (2012) have examined the differences between types of self-talk. Though, no difference between the groups was found. 
Although not statistically different, the imagery group did improve scores the most. On average the imagery group scores improved by 23.8 which is more than the self-talk group which improved 17.6 and confidence profiling which averaged an increase of 11.8.

During the intervention, a sprinter from the club had participated in the European indoor championships and won gold in the $60 \mathrm{~m}$. This became a popular theme during conversations with athletes involved in the intervention. It was thought that with the success of the sprinter, some athletes who are involved in sprinting disciplines would be more realistic with their ambitions so post scores would show less effect. Despite initial thoughts, no significant difference was found, $p>0.05$. However, athletes participating in sprinting disciplines increased on average by 10 points, this is considerably lower than a 25 point increase by non-sprint athletes.

A possible reason why no significant difference was found between groups could be that each intervention group incorporated some sort of positive self-talk alongside their technique. Studies have stated that positive self-talk is most effective when used in combination with another intervention technique (see Hatzigeorgiadis et al, 2011) as forms of self-talk are naturally used with intervention techniques despite not being as well structured as a self-talk intervention. This would mean that the imagery group had selftalk concepts which would've enhanced post scores.

Previous studies such as Van Raalte et al (2000) and Weinberg (2012) made clear that selftalk when used as an intervention is very difficult due to the athlete's ability to change their mind moment to moment. Something as minor as a thought about the feel of their shoes could ruin a positive self-talk intervention (see Engquist, 1997 as cited in Van Raalte, 2000).

It is also a point that to enhance an athlete's confidence, negative self-talk can be useful when applied in small doses. For example Van Raalte et al (2000) claimed that if an athlete performs badly then almost instantly performs well, the increase in confidence will be greater than continuum positive self-talk. This could have been a reason why the increase from pre to post test scores were not as great as the imagery. When observing specific positive self-talk logs, phrases were "I will perform better and throw further than last time". There are two main issues identified with statements like this: 1) If this athlete does perform better, confidence won't increase as much due to the athlete expecting to perform better. Whereas negative self-talk or a phrase structured similar to "I am not expecting to throw far anyway" would enhance confidence more if that athlete did perform better (which is the purpose of the intervention). 2) If the athlete does not perform better, confidence will take a huge knock. The researcher could have had more control over what the athlete is logging by adapting a different philosophical style such as an eclectic approach, however that can eliminate athletes control over the intervention. This intervention was more concerned with a humanistic approach.

Another possible reason why no significant difference was found could be the fact the each group was structured the same. Each group participated in an education period followed by one meeting a week to practice the techniques. When discussing confidence profiling and self-talk, this suits. However when an athlete begins imagery practice for the first time, it is important that the first few meetings are short but frequent (i.e. twice a week for 15-20minutes) as longer sessions are usually ineffective at the beginning (see Callow and Roberts, 2010; Evans, Jones and Mullen, 2004; Bull, 1989). If the sessions had 
been structured in this way, a significant difference favouring imagery may have been seen.

Confidence profiling was originally created as a confidence enhancing technique which provides concentrate assessment of the athlete. Hays et al (2007) does claim that it is useful when used as an enhancing technique purely. No previous studies have done this however. Throughout this study, it was clear that using confidence profiling as a measure is really important to gain maximum outcomes. During the intervention, it was almost a thought process for the athletes as it was clear anything written down would not be referred to in later sessions. Although this did enhance confidence scores in the TSCI and SSCI, monitoring should have been completed. If completed with monitoring, a superior increase from pre to post test scores would have surely been seen. Hays et al (2010) does warn of this and does claim it can almost be like a moment of thought with scoring becoming irrelevant and unnecessary for the athlete.

\section{CONCLUDING REMARKS}

The aim of this investigation has been to discover which confidence enhancing technique is most effective when used as an intervention on amateur athletes. The strategies which were chosen were positive self-talk, imagery and confidence profiling. Valid scoring was used (TSCI + SSCI) as developed by Vealey (1998). Results from a mixed model ANOVA displayed a significant difference in pre and post scores but no significant difference between the intervention groups. Imagery scores did improve the most however. Future applied research should evaluate the effectiveness using interventions lasting more than four weeks as well as adapt the procedure to suit the imagery group. Weinberg et al (2012) does outline the advantages of having short term interventions but studies such as Bull (1991) repeatedly refers to the importance of including an education period. By including an education period, skills which are learnt by athletes become of greater use. To conclude, each confidence enhancing technique improved confidence scores, meaning a successful intervention from the researcher's perspective. However, the aim of this study was to identify which is proven to be most effective, supporting coaches and psychologists when choosing intervention techniques. No statistical difference was found, meaning each are of equal effect.

\section{REFERENCES}

Bandura, A. (1977) 'Self-efficacy: Toward a Unifying Theory of Behavioural Change', Psychological Review 84 pp. 191-215.

Bandura, A. (1984) 'Recycling Misconceptions of Perceived Self-Efficacy', Cognitive Therapy and Research 8 pp. 231-255.

Bandura, A. (1986). Social Foundations of Thought and Action. Englewood Cliffs, NJ: Prentice Hall.

Beattie, S., Hardy, L., Savage, J., Woodman, T., Callow, N. (2011) 'Development and Validation of a Trait Measure of Robustness of Self-Confidence', Psychology of Sport and Exercise 12(2) pp. 184192.

Bull, S. J. (1989) 'The Role of a Sport Psychology Consultant: A Case Study of an Ultra Distance Runners', The Sport Psychology 3 pp. 254-264.

Bull. S. J. (1991) 'Personal and Situational Influences on Adherence to Mental Skills Training', Journal of Sport and Exercise Psychology 12 pp. 121-132.

Burton, D., Naylor, S. (1997) 'Is Anxiety Really Facilitative? Reaction to the Myth That Cognitive Anxiety Always Impairs Performance', Journal of Applied Sport Psychology 9 pp. 295-302. 
Callow, N., Roberts, R. (2010) 'Imagery: Perspectives, Order, and Angle', Psychology of Sport $\mathcal{E}$ Exercise 4 pp. 325-329.

Cumming, J., Hall. C., Shambrook, C. (2004) 'The Influence of an Imagery Workshop on Athletes', Journal of Sport Psychology 6(1) pp. 52-73.

Evans, L., Jones, L., Mullen, R. (2004) 'An Imagery Intervention During the Competitive Season with an Elite Rugby Player', The Sport Psychologist 18 pp. 252-271.

Feltz, D.L., Landers, D.M. (1983) 'The Effects of Mental Practice on Motor Skill Learning and Performance: A Meta-Analysis', Journal of Sport Psychology 5 pp. 25-57.

Feltz, D.L., Lirgg, C.D. (2001). Self-Efficacy Beliefs of Athletes, Teams and Coaches. In R.N. Singer, H.A. Hausenblas, C.M. Janelle (Eds.), Handbook of Sport Psychology (pp. 304-361). New York: John Wiley \& Sons.

Fung, L., Chueng, S.Y. (2001) 'Confirmatory Factor Analysis of the Trait Sport Confidence Inventory and State Sport-Confidence Inventory on a Chinese Sample', International Journal of Sport Psychology 32(4) pp. 304-313.

Gould, D., Hodge, K., Peterson, K., Giannini, J. (1989) 'An Exploratory Examination of Strategies Used by Elite Coaches to Enhance Self-Effiacy in Athletes', Journal of Sport and Exercise Psychology 11 pp. 128-140.

Greenspan, M. J., Feltz (1989) 'Psychological Intervention with Athletes in Competitive Situations: A Review' The Sport Psychologist 3 pp. 219-236.

Hardy, J., Hall, C. R., Alexander, M. R. (2001) 'Exploring Self-Talk and Affective States in Sport', Journal of Sports Sciences 19(7) pp. 469-475.

Hardy, J., Gammage, K., Hall, C. (2001) 'A Descriptive Study of Athlete Self-Talk', The Sport Psychologist 15 pp. 306-318.

Hardy, J., Roberts, R., Hardy, L. (2009) 'Awareness and Motivation to Change Negative Self-Talk', The Sport Psychologist 23 pp. 435-450.

Hardy, L. (1997) 'The Coleman Roberts Griffith address: three myths about applied consultancy work.' Journal of Applied Sport Psychology 9 pp. 277-294.

Hatzigeorgiadis, A., Zourbanos, N., Galanis, E., Theodorakis,Y. (2011) 'Self-talk and sports performance: A meta-analysis', Perspectives on Psychological Science 6 pp. 348-356.

Hays, K., Maynard, I., Thomas, O. and Bawden, M. (2007) 'Sources and Types of Confidence Identified by World Class Sport Performers', Journal of Applied Sport Psychology 19(4) pp. 434-456.

Hays, K., Thomas, O., Butt, J., Maynard, I. (2010) 'The Development of Confidence Profiling for Sport', The Sport Psychologist 18(3) pp. 373-392.

Hays, K., Thomas, O., Maynard, I., Butt, J. (2010) 'The Role of Confidence Profiling in CognitiveBehavioural Interventions in Sport', The Sport Psychologist 24(3) pp. 393-414.

Holmes, P., Collins, D. (2001) 'The PETTLEP Approach to Motor Imagery: A Functional Equivalence Model for Sport Psychologists', Journal of Applied Sport Psychology 13 pp.60-83.

Horn, T. (2008) Advances in Sport Psychology. $3^{\text {rd }}$ ed. Champaign, IL: Human Kinetics.

Jenny, O., Krista, J., Munroe-Chandler, B., Hall, C, R., Hall, N. D. (2013) ‘Using Motivational GeneralMastery Imagery to Improve the Self-efficacy of Youth Squash Players', Journal of Applied Sport Psychology 26(1) pp. 66-81.

Jones, G. (1993) 'The Role of Performance Profiling in Cognitive Behavioural Interventions in Sport', The Sport Psychologist 7 pp. 160-172.

Jones, J. G. (1996) 'Competitive anxiety in sport', European Perspectives on Exercise and Sport Psychology pp. 128-153. 
Jones, G., Hanton, S. (2001) 'Pre-Competitive Feeling States and Directional Anxiety Interpretations', Journal of Sports Sciences 19 pp. 385-395.

Karageoeghis, C, I., Terry, P, C. (2011) Inside Sport Psychology. Champaign, IL: Human Kinetics.

Lirgg, C.D. (1991) 'Gender Differences in Self-Confidence in Physical Activity: A Meta-Analysis of Recent Studies', Journal of Sport and Exercise Psychology 8 pp. 294-310.

Martin, J. J., Gill, D. L. (1991) 'The Relationships Among Competitive Orientation, Sport-Confidence, Self-Efficacy, Anxiety, and Performance', Journal of Sport and Exercise Psychology 13 pp.149-159.

Martin, K. A., Moritz, S.E., Hall, C.R. (1999) 'Imagery Use in Sport: A Literature Review and Applied Model', The Sport Psychologist 13 pp. 245-268.

Morris, T., Koehn, S. (2004) Self Confidence in Sport and Exercise. In Sport Psychology: Theory, Applications and Issue. $2^{\text {nd }}$ ed. Brisbane, AU: Wiley.

Van Raalte, J. L., Brewer. B. W., Lewis, B. P., Linder, D. E., Wildman , G., Kozimor, J. (1995) 'The Effects of Positive and Negative Self-Talk on Dart Throwing Performance', Journal of Sport Behaviour 18, 50-57.

Van Raalte, J. L., Cornelius, A. E., Brewer, B. W., Hatten, S. J. (2000) 'The Antecedents and Consequences of Self-Talk in Competitive Tennis', Journal of Sport and Exercise Psychology 22 pp. 345-356.

Vealey, R. S. (1986) 'Conceptualization of Sport-Confidence and Competitive Orientation: Preliminary Investigation and Instrument Development', Journal of Sport Psychology 8 pp. 221246.

Vealey, R. S (2001) Handbook of Sport Psychology. NY. New York: Wiley.

Vealey, R. S., Hayashi, S. W., Garner-Holman, M., Giacobbi, P. (1998) 'Sources of sport-confidence: Conceptualization and Instrument Development', Journal of Sport and Exercise Psychology 20(10) pp. $54-80$.

Vealey, R., Vernau, D. (2010). Chapter 54: Confidence. In: Hanrahan S. J., Andersen. M. B Routledge Handbook of Applied Sport Psychology (pp. 518-527). New York: Routledge.

Weinberg, R. S., Gould, D. (2011) Foundations of Sport and Exercise Psychology. $5^{\text {th }}$ ed. Champaign, IL: Human Kinetics.

Weinberg, R., Miller, A., Horn, T. (2012) 'The Influence of a Self-Talk Intervention on Collegiate Cross-Country Runners', International Journal of Sport and Exercise Psychology 10(2) pp. 123-134.

Wilson, R. C., Sullivan, P. J., Myers, N. D., Feltz, D. L. (2004) 'Sources of Sport Confidence of Master Athletes', Journal of Sport and Exercise Psychology 26 pp. 369-384. 